\title{
Agenda setting in the world of online news: New questions for new environment
}

\author{
Danka Ninković Slavnić ${ }^{1}$ \\ University of Belgrade, Serbia
}

doi: $10.5937 /$ comman11-12462

Abstract: This paper explores whether agenda setting theory is a fruitful approach to understand online news communication. To answer this question, the distinction between vertical and horizontal media is used and applied to online communication in order to establish their role in news circulation. Vertical media are defined as news media targeting the whole population, while horizontal media are those that enable horizontal flow of communication among different subjects, including citizens. The role these two types of media play in setting issue and attribute agenda is discussed. Additionally, their interconnection is considered in the context of constructing media agenda. Despite the fact that online communication flow is complex and goes in different directions, this paper marks horizontal media as a significant force in making community issue agenda and in interpreting attribute agenda set by vertical media. At the same time, vertical online news media are speculated to be still the major factor when it comes to public issue agenda, the agenda that is specific medium of connection for one society. This paper is trying to provide theoretical framework for thinking about agenda setting and to stimulate further empirical research that will shed additional light on the process.

Keywords: agenda setting, online news, horizontal media, vertical media, social networking websites.

\footnotetext{
1 Contact with author: dninkovic@yahoo.com.
} 


\section{Introduction}

Agenda setting theory is approaching its $50^{\text {th }}$ anniversary. The seminal research was conducted in 1968 during presidential election in Chapel Hill, North Carolina when Maxwell McCombs and Donald Shaw (1972) were looking for correlations between mass media agenda and voters' judgment about the most relevant topics of campaign. Their findings confirm the hypothesis that mass media set public agenda:

"In short, the data suggest a very strong relationship between emphasis placed on different campaign issues by the media (reflecting to the considerable degree the emphasis by candidates) and the judgments of voters as to the salience and importance of various campaign topics." (McCombs \& Shaw, 1972: 181)

In accordance with this result, agenda setting theory redefined the dominant understanding of media influence. Media effects were no longer conceptualized as influencing what people are to think, but instead, as the founders of theory founders say, quoting Bernard Cohen (1963) 'what to think about' (McCombs \& Shaw, 1972: 177).

With more than 425 empirical studies about the agenda setting conducted worldwide, this theory is among the most frequently used approaches for studying media effects (McCombs \& Reynolds, 2009). Plenty of empirical data confirm that public affairs emphasized by the news become salient among the public.

Although agenda setting theory began as research of electoral communication and has been often used for exploring political campaigns, it was also applied on other news issues and further developed to encompass different aspects of mass communication and its influence on public knowledge and opinion. Looking back at the theory evolution, one of its founders Maxell McCombs pointed out that theory expanded into five distinct stages, all of them coexisting at the same time, active and open for research: basic agenda setting effects, attribute agenda setting, psychology of agenda-setting effects, sources of media agenda and consequences of agenda setting effects (McCombs, 2005). While basic agenda-setting refers to transfer of media issues salience to public, attribute agenda-setting explores how these issues are framed, described and explained. The further theory development included audience. Why some people accept 
while others ignore media agenda is examined by looking at psychological factors that influence the process. The effectiveness of agenda setting is explained within the theoretical strand that is dealing with the consequences. The field of research was additionally expanded when the question who sets media agenda came into focus. As McDonald noticed, "agenda setting was transformed from a hypothesis to a research area" (McDonald, 2004: 193). It evolved with the aim to explore and explain interconnected processes which shape people's perception, knowledge and attitudes about public affairs.

\section{Agenda setting and the internet}

Although highly influential theory, agenda settings was challenged by the rise of the internet. Majority of research that confirmed agenda setting effects were conducted in different mass media environments, which brings up logical question - which segments of the existing theory are applicable and valid when we talk about internet communication.

Discussion about this topic is demarcated by the fact that not only is the internet itself different than mass media, but also, the internet is going through rapid change that influences, among other things, the way people interact with news. Pew Research Center states that three technology revolutions have occurred since the beginning of XXI century - broadband, mobile connectivity and social networking (Pew Research Center, n.d.). All these changes affected the amount and availability of information, they relativized the borders between private and public communication and opened the possibility for 'people formerly known as audience' (Rosen, 2006) to share, comment and produce news in an unprecedented way in media history.

The internet is becoming more relevant as a source of news. It is the second most popular news source, behind television (Mitchell et al., 2016; Newman et al., 2016) and results show "the balance shifting slowly, but inexorably towards online" (Newman et al., 2016: 86). Another trend detected during the last years is the rise of social media as news source. The Reuters Institute research that included 26 countries shows that half $(51 \%)$ of all people who participated in the survey use social media as news source each week (Newman et al., 2016).

Having in mind the changed media environment and specially the facts that a) plenty of media, legacy and digital-born, are present online; b) web 2.0 provided the space for non-media subjects (like institutions, organizations and 
citizens themselves) to produce and distribute their news stories and c) news audience can actively select between plenty of news sources; the question is whether agenda setting theory is still relevant and applicable.

In order to address this question this paper will focus on the three stages of theory identified by McCombs (2005): basic agenda setting effects, attribute agenda setting and sources of media agenda. These stages are pivotal for understanding of the theory and they refer to processes which should be scrutinized in order to find out how the internet has altered them. Is process of fragmentation strong enough that we can say that millions of 'The Daily Me' have media menu so different that we cannot talk about unique public issues agenda? Can social media influence attribute agenda? Are media relying on the same sources as before or are they including new ones? For discussion of these issues recent theory developments and available empirical data will be used.

\section{Basic agenda setting}

Basic agenda setting is the core of the theory and it refers to the issues represented by media. Simply put, the salience given to certain topics will shape public perception of the most important issues in one society. This assumption lies in the foundation of numerous research that confirmed the existence of agenda setting effects. But this hypothesis was formulated and empirically confirmed in different media environment. Can we assume that the same applies for online news communication? Do media still set issue agenda or is contemporary communication too fragmented for unique agenda to exist?

For examination of this question some already formulated theoretical taught can be useful. In order to expand agenda theory scholars included additional aspects into consideration and provided more detailed insights into the complex process of communication flaw. One step forward is made when audience activity is taken into account, and its capability to select from media and other sources to get more personalized agenda was included into deliberation. This process, called agenda melding, meaning that audience choose from numerous agendas and compose their own, is described by the most prominent scholars engaged in agenda setting theory (Shaw et al., 1999; Shaw \& McCombs, 2008; Weaver et al., 2010; McCombs, Shaw \& Weaver, 2014).

Agenda melding theory is an attempt to explain people's exposure to different agendas. As such it represents the broadening of interests beyond mass 
media to include different types of communication. In order to explain how that process works Shaw and his colleagues put the concept of community into the center of their attention. Although communities can differ by numerous criteria, for example if they are geographical or topic communities, formal or imagined, do we chose to belong to them or we are in them by incident, etc. they are all put together via medium of connection 2 (Shaw et al., 1999: 12). Besides mass media and specialized media, other persons or groups are also the medium of connection. Therefore we can connect with others by using different media or interpersonal contacts in order to become part of a community. Some communities are grounded in our everyday life, while others can be highly abstract. Each of them has its own agenda. "The more distant the group, for example, a nation versus one's place of work, the more general is the agenda, and the more likely that agenda is represented in the general mass media" (Shaw et al., 1999: 12-13). An example of general community people are identifying with is nation (or national state). In this case, mass media are bonding together and connecting this 'imagined community' (Anderson, 1998). On the other side, when belonging to primary groups, other persons are the medium of connection into family or school class. There are various other communities somewhere in between this two endpoints with different degrees of generality and people connect with them using different media of connection.

The differentiation of communities based on the correlation between the level of generality and the type of medium of connection can be a fruitful starting point for considering online news communication. In online world there is one flow of communication about public issues initiated by legacy or digitalborn news media, which means they are making communities at general level, similar to traditional media. At the same time, there is another stream of online communication going on between interconnected people which makes more specific communities. Therefore the distinction between vertical and horizontal media, that emerged from further development of agenda melding (Shaw \& McCombs, 2008; Weaver et al., 2010; McCombs, Shaw \& Weaver, 2014; Vargo et al., 2014) can be applied on online news communication.

Vertical media are those that tend to produce news of general relevance, they cover major events and try to reach the wide audience. They "attempt to

2 Shaw and his colleagues attribute the origin of this phrase to communication scholar Keith Stamm who used it to claim that children are the medium of connection with the local community. 
reach everyone within media reach, shouting from the top of a pyramid, as it were, to everyone below" (Weaver et al., 2010: 15). Horizontal media are those built by a specific community around the content they produce, or as in case of social networks around people with who someone wants to be in contact. In that sense it could be said that vertical media are significant in forming general, public issue agenda, while horizontal media provide community agenda.

Vertical media are still very important source of news. They are the medium of connection that brings together citizens living in one state. 3 Established media brands are prominent news source in online environment. Reuters Institute for the Study of Journalism claimed that

"although aggregators and social media are important gateways to news, most of the content consumed still comes from newspaper groups, broadcasters, or digital born brands that have invested in original content. Across all of our 26 countries over two-thirds of our sample (69\%) access a newspaper brand online each week, with almost as many (62\%) accessing the online service of a broadcasting outlet" (Newman et al., 2016: 27).

Research about setting agenda in digital environment (Vargo et al., 2014) used big data from Twitter to explore agenda melding and network agenda setting4. The research is focused on media and journalists' influence in online communication and their capability to set agenda during electoral period. The finding is that "candidate supporters' network issue agendas were strongly aligned with the vertical media's network issue agenda during the election period" (Vargo et al., 2014: 13). This means that voters acknowledge the choice of topics presented by the media as the most relevant ones and they also accept the interconnection between issues made by vertical media.

The strength of vertical media to set issue agenda was also confirmed when agenda of low and high internet users was compared with agenda of the state's major newspapers. "There is a difference, but hardly an awesome one. For low internet users the correlation with newspaper agendas is +.90 . For high internet

\footnotetext{
3 That is the reason why McCombs, Show \& Weaver (2014) refer to community enabled by vertical flow as civic community.

4 The network agenda setting (NAS) is novel addition to the existing body of theoretical work about agenda setting. "The central hypothesis for the Network Agenda Setting Model is that the salience of the interrelationships among constructs - or the associative network regarding a certain topic - can be transferred from the media agenda to the public agenda" (Guo, Vu \& McCombs, 2012: 57). Therefore media do not just point at issues and give us frame of references to think about them, but also connect different issues and attributes making specific associative network.
} 
users, who still seemed shaped by newspaper agendas, the correlations are +.70 " (Coleman \& McCombs, 2007 in Shaw \& McCombs, 2008: 6).

As the quoted studies show, we are still getting familiar with major social events from the reports produced by vertical type of media. Presidential campaign in America, war in Syria, Brexit, migrant crisis in Europe, are some examples of very relevant international public issues we learn about from vertical media. As Walter Lippmann put it "the world we have to deal with politically is out of reach, out of sight, out of mind. It has to be explored, reported and imagined" (Lippmann, 1922/1998: 29). Media are still those entities that explore and report to us about the world beyond our immediate reach and there is no one competing to take over that role. That is why news media are still bridging immense world we live in and 'pictures in our heads' (Lippmann, 1922/1998). Even though there are countless different vertical media, the issue agenda is quite homogeneous among traditional news media and also among their online issues (McCombs, 2005), meaning that even in the online environment there is a high degree of consensus about the most relevant issues for society.

However, this does not mean that nothing has changed in online news communication. On contrary, the way horizontal flow is going is significantly altered.

Although the first empirical research aimed to explore vertical and horizontal media influence on audience agenda (Weaver et al., 2010) took as exemplars of horizontal media cable news networks and talk shows, horizontal media are not limited to media organizations. "Bloggers, journalists, talk show hosts, and celebrities alike transmit information horizontally. This important distinction broadens horizontal media beyond niche media to include individuals that broadcast news to specific communities of people" (Vargo et al., 2014: 3). Beside those mentioned by Vargo and colleagues, numerous non-media subjects, like NGO's, groups, institutions neglected by vertical media and citizens themselves can participate in making horizontal media. They do so, whenever they use social media to communicate. Huge number of voices coming from various backgrounds make issue setting on social media very dynamic and complex. How those community agendas are built and how they relate to vertical media agenda are the questions are just recently being empirically explored and theoretically explained (Sayre et al. 2010; Vargo et al., 2014; McCombs, Shaw \& Weaver, 2014). 
McCombs, Shaw and Weaver (2014) pointed at "origins for three distinct subsets of the social media issue agenda". The first "originate in citizens' longstanding-and often passionate-interest in particular issues", the second is a consequence of direct participation or observation of events, while, in their opinion, still "a primary source of the messages that make up the public issue conversation on social media are the news events of the day" (McCombs, Shaw \& Weaver, 2014: 789). As they conclude "the first two of the social message subsets just described are largely original contributions by the public to the social media issue agenda. The third is a broadening and redefinition of the traditional agenda-setting role of the news media" (McCombs, Shaw \& Weaver, 2014: 790).

It can be said that the first two scenarios are newly opened possibility for citizens, organization and groups to influence social media issue agenda with content production. They can post online information about some phenomena or issue relevant to them or they can inform others about specific events. Sayre and his colleagues have been following YouTube and mainstream media in order to study communication about Californian proposition which eliminates right of same sex couples to marry. They conclude that "a social media platform is now being used to bring attention to an issue when the mainstream media are not" (Sayre et al., 2010: 26). Although this topic occasionally found its place in mainstream media agenda, it was continuously present on YouTube during the research period implying that for those to whom issue was highly relevant, social network was the medium to discuss it.

Different topics will get public attention and become part of vertical media reporting from time to time, but for some communities they are issue of high relevance all the time. In some instances this horizontal communication can become online version of what Nancy Fraser calls subaltern counterpublics: "On the one hand, they function as spaces of withdrawal and regroupment; on the other hand, they also function as bases and training grounds for agitational activities directed toward wider publics" (Fraser, 1992: 124). The horizontal online communities in this situation can be places for socializing experience, exchange of arguments and staying connected with similar people. Additionally, they are also places for minor topics, those issues that are not 'big enough' to pass traditional gatekeepers, but that can find their place in this community agenda. 
The second subset of issues posted by public as a part of social media agenda are those when citizens are participants or witnesses of events. These examples are often studied as cases of citizen journalism, especially when they are about sudden and catastrophic events, like terroristic attacks in New York (2001), London (2005) or Paris (2015) or natural disasters (Hurricane Katrina, 2005). Although citizens' reports precedes vertical media, those types of events are regularly part of mainstream media issue agenda, and in these cases, it would be exaggerated to presume that social media cause vertical media to report an issue. 5 However, it is possible that citizen journalism can influence the way story was told, in the sense that coverage was more immediate and personalized. Therefore it can be speculated that citizen journalism can influence attribute agenda, but comparative empirical studies are needed to find out if this assumption holds.

The third origin of public issues on social media are news stories made by vertical media. In this case issue agenda of mainstream media is not just duplicated in a social network, but modified. Some news are shared and become more visible, while others are ignored in community agenda. Certain issues, reported as low in significance can become prominent in specific online community and the opposite can happen as well. The communities have power to reshape public issue agenda.

Dynamics of social media, when we speak about issues presented in vertical media, strongly resemble Lazarsfeld's two-step flow communication theory and assumption about opinion leaders capable to modify and interpret media agenda. The importance of opinion leaders in online news flow is confirmed by research that "combines analysis of the size and structure of the network and its sub-groups with analysis of the words, hashtags and URLs people use' in order to get network maps that 'provide new insight into the landscape of social media" (Smith et al., 2014). When communication on Twitter was scrutinized with innovative data analysis tools, it was established that there is minority of users who have specific position and more pronounced role in communication.

"Key users occupy strategic locations in these networks, in positions like hubs and bridges. Network maps locate the key people who are at the center of their conversational networks - they are 'hubs' and they are notable

5 This does not mean that social media cannot influence vertical media agenda at all. The issue will be discussed in section about media agenda. 
because their followers often retweet or repeat what they say. Some people have links across group boundaries - these users are called 'bridges'. They play the important role of passing information from one group to another. These users are often necessary to cause a message to 'go viral'." (Smith et al., 2014)

The role opinion leaders play in political communication was examined by Karlsen (2015) on the representative sample of 5.700 people in Norway.

"The results show that they had larger online networks than others; they had more friends on Facebook and more followers on Twitter; they were more active when it came to diffusing political messages in these networks as they commented and discussed, as well as linked to, content about politics and current affairs to a much greater extent than other groups." (Karlsen, 2015: 14)

From the perspective of agenda setting theory the most important results of opinion leaders' activity is building issue agenda in their community by influencing on visibility of selected issues (and their attributes). By doing this they make some news visible to people who are not particularly interested in news and who stumble upon them because they become salient in their network. This unintentional and unplanned reading of the news is a phenomenon enabled by social media because they do not cluster communication by specific segments or topics, but instead make continuous flow of different information. For example, 78\% of Facebook news users mostly see news when they use this social network for other reasons and for them "getting news is an incidental experience" (Matsa \& Mitchell, 2014). This specificity of social media additionally complicates the process of agenda building. Intentional selection of sources is just one component people use to influence their own agenda. The other components are less predictive and harder to explain because they heavily depend on the momentum when issue gets in someone's community.

The basic agenda setting theory conceptualizes the whole process as one way influence, from media to public, but the dynamic of building social media agenda is more complex as it combines different influences. Various sources, including media-related, as well as citizens, especially those who establish themselves as opinion makers, together with algorithms used, are factors that decided which issues will become prominent in someone's network. In attempt 
to explain the complex dynamics of social network communication Wohn and Bowe proposed "a theoretical framework called 'crystallization"” (Wohn \& Bowe, 2016), which posits that the way people develop "perceptions of reality is an emergent process rather than one-directional top-down approach described by agenda setting" (Wohn \& Bowe, 2016: 3). They emphasize the complexity of horizontal flow of communication where there is no single source of information but numerous that interfere with each other. As a result, there is a difference between community agenda since everyone's social network "act as 'micro' agenda setters at both the first and second level” (Wohn \& Bowe, 2016: 3).

How is issue agenda of vertical media related to agenda of horizontal media? As previous observations show, vertical media are still powerful in setting public issue agenda, but that agenda can be modified in horizontal online media. Although awareness of an issue can remain high, its salience can be changed in community agenda. How often this happens, in what circumstances and with which consequences are the questions still waiting for further exploration. Can we say that public issue agenda is composed of topics defined by media as prominent, kind of common issues for the whole population, and those community issues that can be related with identity, minority rights, economic status, professional interests etc. which can get more attention from time to time and become part of vertical media agenda? Is it possible for some topics to grow big and become so widespread that they can be considered to be public, independently from vertical media? If some political system is shrinking the freedom of public speech and media freedom, is it possible for horizontal communication flow to become a new, parallel public space where issues banned from vertical media are raised? All this open questions indicate complexity of online news communication process. As a theory dealing with the matter of public issues, agenda setting theory and its offspring (agenda melding) may become starting points for better understanding how the process of defining what issues deserve general attention looks like on internet.

\section{Attribute agenda setting}

Besides the capability of media to tell public what to think about, agenda setting theory, during its development, included another aspects into consideration. Basic assumption was further expanded in a way to address not only issues media report about, but also the way they do it. 
"Both the selection of objects for attention and the selection of attributes for thinking about these objects are powerful agenda-setting roles. An important part of the news agenda and its set of objects are the perspectives and frames that journalists and, subsequently, members of the public employ to think about and talk about each object. These perspectives and frames draw attention to certain attributes and away from others." (McCombs et al., 1997: 704)

With the inclusion of these elements into research, the basic agenda setting was accompanied with so called attribute or second level agenda setting6 that "suggests that the media also tell us how to think about some objects" (McCombs et al., 1997: 704).

Attribute agenda setting hypothesizes that media influence people perception of public figures and issues. The influence is not straightforward effect on someone's thoughts, but a kind of directional input toward specific stands. People need media to help them form opinion about candidates, events and public issues. Media, by making selections, emphasizing certain aspects, while neglecting others, play important role in defining reality. Media stories characterize objects of reporting in a particular way and public inclines to follow the connection set by media, in a manner to ascribe attributes to an object in a similar way as media did.

During 1990's this hypothesis became part of empirical research that were trying to establish if media convey attributes agenda to the public. Study in Spain (1996) was among the first ones to look for correlation between public perceptions of candidates for prime minister and media representations of them. The research established that the median correlation for local newspapers was 0.70 and for national 0.81 (Weaver, McCombs \& Shaw, 2004: 261-262) which revealed the high degree of resemblance among media description and voters' perception of candidates. The results of other studies exploring the same correlation are not uniform7, they vary, among other things, depending on media system, media, the type of communication that was under scrutiny,

\footnotetext{
6 The second level of agenda setting link this theory with concepts of framing and priming. For similarities and differences in their meaning see Weaver (2007).

For examples of research done in Japan, Israel, Italy, Taiwan, Spain, Germany and United States, see Weaver, McCombs \& Shaw (2004).
} 
but overall conclusion confirms assumption that we use guidelines provided by media in order to better understand issues from news reports.

If we leave theoretical nuances aside8, and accept the basic premise about the role of media in attributing people and issues in particular way, the question is what can be said about that process having on mind the distinction between vertical and horizontal media.

The first exploratory research that was dealing with voters use of vertical and horizontal media during presidential elections in America 2008 and with the role they have in setting first and second level agenda suggests that voters use vertical media to deepen their knowledge about issues and that vertical media provide attributes about those issues. The conclusion about horizontal media suggests that "voters attach attributes to candidates-eloquence, old, experienced - in ways that match up with horizontal media use, suggesting that voters find a horizontal medium that enables voters to nest their choices into a comfortable personal narrative" (Weaver et al., 2010: 17-18). It seems that voters use attributes offered by horizontal media to shape their opinions about candidates, and, at the same time, when choosing among horizontal media they are looking for those compatible with their preexisting preferences. In that way image about a candidate is consistent with overall political attitude.

If we expand this discussion in order to include news in general and the way they circulate on the internet, can it be speculated that although vertical media are still major source that set public issue agenda and provide wide reaching details about topics of reporting, horizontal media are significant in shaping the meaning of these events? Are horizontal online media, including social networks as the most important representative, more than issues communities? Are they also the interpretive communities that are dealing not only with specifically their topics, but with issues set as public by vertical media as well? Can we assume that horizontal media have stronger impact on attribute agenda then vertical?

Although it is not possible to quantify and offer simple answer, it is possible to speculate that when it comes to online news communication, the most prominent role of vertical media is to set issue agenda, while the dominant role of horizontal media is to interpret issues, ascribe them a set of attributes that de-

\footnotetext{
Such as distinction between substantive and affective dimension of attributes (McCombs et al., 1997), or the concept of compelling arguments (Salma Ghanem, 1996 in McCombs, 2005).
} 
fine the meaning and provide wider context. Although further research should be done in order to reject or confirm the stated hypothesis, some recent studies are in line with this assumption (Smith et al., 2014; Wohn \& Bowe, 2016).

The same issue can be communicated in different ways on social media. The analysis of communication networks structure on Twitter pointed at two structure types relevant for online news - polarized crowds and community clusters (Smith et al., 2014). Polarized crowds are formed around political controversies when people take one of two highly confronted stance. They are either pro or contra somebody/something. The share of uninterested or undecided is relatively small and they usually do not participate in online discussion. In these situations people connect with the like-minded and form a sort of echo chamber. They ignore existence of other group and their argumentation. Although they are discussing the same topic, they use different resources and hashtags. Issue agenda is shared while attribute agenda is conflicting. The strong line of demarcation is drew any time when these highly charged issues come into focus.

The other type of structure is community cluster. Community clusters are often built around global issues and events that are the subjects of media reporting. Although they are all reporting about same topics, there are numerous approaches. "These can illustrate diverse angles on a subject based on its relevance to different audiences, revealing a diversity of opinion and perspective on a social media topic" (Smith et al., 2014). For example, war in Syria and refugee crisis it caused is global issue, but the way it is reported varies among states, media types and ideological positions, depending on official politics and political interests, predominant sentiments, emphasized aspects etc.

The both mentioned structures confirm that the same issue presented in vertical media reporting9 can be differently interpreted in social media. Some interpretations can be in accordance with the way topic was attributed by vertical media, while some can challenge it.

The similar conclusion about influence of horizontal flow is found in the research dealing with social networks and their impact on understanding of reality. When students who participates in the research were asked to share their views about three different news event, the researchers found the strong influence of social networks on their judgment. "While there was some shared

\footnotetext{
9 Vertical media presented on social networks are still reconsidered as vertical since they use the social media as another cannel to convey the same story. The same applies for mobile application of general news media.
} 
reality in that participants were all aware of the event, their understanding and interpretation of their event was, to a large extent, informed by their network" (Wohn \& Bowe, 2016: 7). Interviews with participant confirmed that they have different perspectives on the analyzed events and that social media were influential factor in shaping that perspective. Therefore Wohn and Bowe conclude that micro agenda setting is a process that influences how people perceive events, and that micro agenda varies among groups.

In setting horizontal attribute agenda opinion leaders play significant role in their communities in a manner similar to that explained when issue agenda was discussed. Opinion leaders, as the most influential participants, can contribute not only to a topic becoming prominent, but also to certain interpretation becoming dominant in a community. Since their output has bigger reach than others in the network, it is logical to assume that attribution and interpretation they make when commenting both vertical media and community issues participate in shaping the perception of a person or event discussed. As already stated, the network is not an egalitarian structure. On contrary, people take different roles - they are readers, commentators, contributors. Those individuals who establish themselves as important knots of the network become the valuable medium of connection for their communities. How they convey agenda of attributes, and how they form their own are important, not yet answered questions that could shed additional light to our understanding of attribute agenda setting.

Social media are expansion of our surrounding because they open the possibility to establish connections with people beyond our reach, to share our beliefs with them, or to be expose to their interests and views. At the same time, they are used by institutions and organizations, including vertical media to spread their messages. Therefore they can be researched as places where verti$\mathrm{cal}$ and horizontal communication intersects and where (issue and attribute) agenda melding can be more directly examined. It can be a point where the dynamics between vertical and horizontal communication is revealing itself in a way that was not possible before.

While we cannot know what happens in a world beyond our reach without some sort of media (in most cases vertical one), when constructing meaning of an event we do not start from scratch. We rely on previously gathered knowledge, experience, our understanding of how it can influence our life, impres- 
sions, emotional impact of news, but also on others with whom we communicate about issues. The interpretations offered by vertical media are not the only resource we use to make sense of events and issues. Horizontal community as well as personal involvement are also important factors that shape our understanding of public issues. The dynamics of this process is complex and it can be said that empirical exploration is at the very beginning, but online communication is suitable environment for this type of research which brings hope that further investigation will help us better comprehend why people understand the certain issues in a way they do.

\section{Setting of media agenda}

The breakthrough step in agenda setting theory was made in early 1980's when additional research question was opened. Along with interest in the way media agenda influences public, the new area of investigation emerged asking who sets media agenda.

"In this new line of inquiry, researchers began to explore the various factors that shape the media agenda. Here the media agenda is the dependent variable whereas in traditional agenda setting research the media agenda was the independent variable, the key causal factor in shaping the public agenda." (McCombs \& Reynolds, 2009: 11)

Media agenda is influenced by news sources - representatives of institutions, politicians, public officials, famous individuals and others about whose work media regularly report or whose opinions they quote in order to explain relevant public issues. Besides sources, media agenda is determined by factors such as media routine, professional journalistic norms and ideological standpoint of media. Media also have impact on each other, which is a phenomenon recognized and explored as intermedia agenda setting.

In current media environment, having in mind all changes brought by web 2.0, there is a new important consideration: can public influence media agenda? Does reverse agenda setting work in online space? Are vertical media accepting agenda set in public conversation on social media?

The notion of reverse agenda setting, which assumes preexistence of public interest recognized by media, is not new, but is actualized now when social media are significant factor of public conversation. Traditional media can observe 
and estimate if same topics or events discussed on social media deserve their attention. At the same time, they can ask for and dedicate some space in media outlets for public input. Although the possibility for public to influence media agenda exist, can we say it happens?

The relation between traditional media and social networks was often framed as the question of intermedia agenda setting between these two types of communication. The major question was who is influencing whom? While there is satisfactory amount of evidence that the relevant traditional news media have impact on online horizontal communication flow, the existence of reverse agenda setting is rarely empirically established.

Meraz (2009) showed the impact that elite traditional newsroom blogs had on independent political blogs, Johnson (2011) revealed that citizens who used CNN's platform iReport.com to talk about 2008 election accepted issues set by traditional media, Kim and colleges "demonstrated that the issue and attribute agendas of candidates in newspapers positively influence the issue and attribute agendas in tweets" (Kim et al., 2016: 4563).

Among those research that find reverse agenda is the one conducted by Groshek and Groshek (2013), even though they were able to confirm that relation only for one topic. "In this study at least, there was only clear evidence that social media influenced the agenda of traditional media in the case of cultural trending topics on Twitter having Granger-caused 10 cultural coverage on CNN" (Groshek \& Groshek, 2013: 21).

Research on the impact of Twitter political communication on mainstream media demonstrates that content travels from Twitter to news media, but amount of information and the ways of presentation and incorporation in media texts vary significantly between countries (Skogerbø et al., 2016). The only consistent finding across all studied countries (Norway, Sweden and Australia) was that elite political sources were dominant. This means that mainstream media continued to rely on already established politicians as a sources, since their messages from Twitter were most often taken over.

When exploring whether traditional news media agenda is overflowing into social media, or communication going in the reverse direction Neuman and colleagues (2014) were searching for time-series linkage between reporting

\footnotetext{
${ }^{10}$ Granger causality is methodological framework often used by econometrician. It assume that "a measure $\mathrm{x}$ is said to 'Granger cause' a measure $\mathrm{y}$, if $\mathrm{y}$ can be better predicted from past values of $\mathrm{x}$ and $\mathrm{y}$ together, than from past values of y alone (Freeman, 1983)” (Neuman et al., 2014: 11).
} 
about 29 political issues. They were following, on one side, representatives of social media (Twitter, blogs, forum commentaries) and traditional media news stories during 2012, on the other. Authors find that dynamics of these conversations are complex and to think about them as one way influence would be misleading. They conclude that

"the relationship between political discussion in traditional commercial media and social media is better characterized as an interaction and differentiated resonance as each in its own way responds to the events of the day rather than a mechanical causal linkage." (Neuman et al., 2014: 19)

Although they find, as a kind of surprise, the prominence of the socialto-traditional media direction, which means "social media Granger cause higher levels of attention in traditional media in 18 of 29 tests" (Neuman et al., 2014: 12), authors do not interpret it as a simple effect. Instead, they argue that "both crowds and the professional journalists are reacting to a shared perception that an event is significant and each is responding according to its own natural dynamic" (Neuman et al., 2014: 12).

However, their conclusion does not state that public do not influence media agenda. It rather emphasizes the fact that the process of influence is not simple, inevitable and one directional. There are examples when social media topics have become mainstream media issue. 11 The question is why they are not caught in research which were trying to establish that connection. One possible reason is that reverse flow, from horizontal to vertical media is not happening on daily basis. It is an exception, not a rule. Therefore, this phenomenon evades researchers who are studying a period of more or less regular communication activities. As occasional type of event, reverse agenda setting should be approached differently if we want to find out under which circumstances it happens, what are necessary conditions, are specific types of media in which it is more likely to occur? Those are some of questions that need further exploration if we want to better understand setting of media agenda in the digital age. In order to do so, agenda setting research needs to expend its area of investigation one more time. For a long time, understanding of media work within agenda setting theory was based on content analysis. Although this approach can reveal regularities and dominant topics, in order to explore reverse agenda setting,

\footnotetext{
${ }^{11}$ Newman and colleagues (2014) mention top 10 reverse-agenda cases in USA and Korea, but do not provide further analysis. In every country there are similar examples.
} 
media production process needs to be additionally scrutinized. The analysis of case studies when public communication on social media had impact on vertical media agenda, as well as media production research, can explain why, when and how journalist take over issues from horizontal online flow and include them in media agenda. Research of this type should provide valuable answers on important question about public influence on media agenda.

\section{Conclusion}

Despite the fact that in contemporary world news are coming to audience through numerous media, the paper is focused on internet news communication. There are two reason for this decision. The first is that number of people getting news online is constantly growing, and the second is that the question of setting agenda in online environment is relatively new and thought-provoking area of research.

Contrary to pioneering empirical research which were exploring certain aspects of agenda setting on social networks, or the impact of social networks on traditional news, this paper was aiming to offer theoretical discussion about the agenda setting process in online communication. The categorization of theory stages (McCombs, 2005) and distinction between two different media types - vertical and horizontal (Shaw \& McCombs, 2008; Weaver et al., 2010; McCombs, Shaw \& Weaver, 2014; Vargo et al., 2014) were taken as starting points in discussion about online news communication.

This approach resulted in a set of questions that each chapter was trying to rise and offer some initial thoughts. Regarding basic or issue agenda setting, the main concern was is if we can still talk about unique agenda and if the answer is positive, how vertical and horizontal media participate in its making. The hypothesis is that vertical media play dominant role in setting public issue agenda in online communication, while horizontal modify it and make their own community issue agenda. If we look at the agenda from the audience perspective - everyone's agenda about public issues is composed of two parts. The fist is made by issues set by vertical media, usually those beyond immediate reach. The second part of agenda consist of topics with stronger personal interests usually communicated within horizontal community. Even though the issues occasionally overlap, they can be distinguished as public and community agenda with each of them having its specificities. Discussion about at- 
tribute agenda is focused on the role of horizontal media and their influence on perception of issues, events and people. The question whether they are strong, even dominant factor in shaping attribute agenda is the central for this part of paper. Since they are considered to be kind of interpretative communities, the stated arguments uphold the assumption about the impact that horizontal, in this case social media, have on the way people perceive different public issues and figures. The main question regarding media agenda is weather the public, represented through horizontal media, has the potential to influence agenda of vertical media. Despite the fact that stories from social media occasionally find their path to vertical media, it is still under-researched process, and attempts to prove existence of reverse agenda setting did not brought conclusive results. The shift in methodological approaches is suggested as a possible direction for the further investigation on this topic.

The whole reflection expressed in the paper has an underlying assumption that the agenda setting theory offers concepts that help us understand what are the main issues in society, what their meanings are and how different types of media participate in formulating them. At the same time, when trying to explain the way the process works in online communication, the paper generated new questions that can be stimulating for further research. Among the most intriguing questions that come to mind are those centered on social media as the dominant type of horizontal media in online communication: how they modify issue agenda of vertical media, what is their role in creating attribute agenda for horizontal communities, how homogenous those agendas are, and who and how influences social media agenda. Even though the role of social media in contemporary online news communication can be studied from diverse perspectives, the feasibility to post some of the highly relevant questions within the agenda setting framework suggest that this theory can be adequate for providing answers to them. 


\section{References}

Anderson, B. (1998). Nacija, zamišljena zajednica. Beograd: Plato.

Groshek, J. \& Groshek, M.C. (2013). Agenda Trending: Reciprocity and the Predictive Capacity of Social Networking Sites in Intermedia Agenda Setting across Topics over Time. Media and Communication, 1(1): 15-27.

Guo, L., Vu, H. T. \& McCombs, M. (2012). An Expanded Perspective on Agenda Setting Effects. Exploring the third level of agenda setting. Revista de Comunicación, 11: 51-68.

Fraser, N. (1992). Rethinking the public Sphere - A Contribution to the Critique of Actually Existing Democracy. In Calhoun, C. (ed.), Habermas and the Public Sphere (pp. 109-141). Cambridge, MA: MIT Press.

Johnson, K. A. (2011). Citizen Journalism, Agenda-Setting and the 2008 Presidential Election, Web Journal of Mass Communication Research, 28. Retrieved from http://www.scripps.ohiou.edu/wjmcr/vol28/.

Karlsen, R. (2015). Followers are Opinion Leaders: The Role of People in the Flow of Political Communication on and beyond Social Networking Sites. European Journal of Communication, 30(3): 1-18.

Kim, Y., Gonzenbach, W. J., Vargo, C. J. \& Kim, Y. (2016). First and Second Levels of Intermedia Agenda Setting: Political Advertising, Newspapers, and Twitter During the 2012 U.S. Presidential Election. International Journal of Communication, 10: 4550-4569.

Lippmann, W. (1922/1998). Public Opinion. New Brunswick \& London: Transaction Publishers.

Matsa, K. E. \& Mitchell, A. (2014). 8 Key Takeaways about Social Media and News. Retrieved from http://www.journalism.org/2014/03/26/8-key-takeawaysabout-social-media-and-news/.

McCombs, M. (2005). A Look at Agenda Setting: Past, Present and Future. Journalism Studies, 6(4): 543-557. 
McCombs, M. \& Shaw, D. (1972). The Agenda-Setting Function of Mass Media. The Public Opinion Quarterly, 36(2): 176-187.

McCombs, M. \& Reynolds, A. (2009). How the News Shapes our Civic Agenda. In Bryant, J. \& Oliver, M. B. (eds.), Media Effects: Advances in Theory and Research (pp. 1-15). London \& New York: Routledge.

McCombs, M., Shaw, D. \& Weaver, D. (2014). New Directions in AgendaSetting Theory and Research. Mass Communication and Society, 17(6): 781-802.

McDonald, D. G. (2004). Twentieth-Century Media Effects Research. In Downing, J.D.H., McQuail, D., Schlesinger, P. \& Wartella, E. (eds), The SAGE Handbook of Media Studies (pp. 183-200). London: Sage.

Meraz, S. (2009). Is There an Elite Hold? Traditional Media to Social Media Agenda Setting Influence in Blog Networks. Journal of Computer-mediated Communication, 14(3): 682-707.

Mitchell, A., Gottfried, J., Barthel M. \& Shearer E. (2016). The Modern News Consumer: Pathways to News. Retrieved from: http://www.journalism. org/2016/07/07/pathways-to-news/.

Neuman, W. R., Guggenheim, L., Jang, S. M. \& Bae, S.Y. (2014). The Dynamics of Public Attention: Agenda-Setting Theory Meets Big Data. Journal of Communication, 64(2): 1-22.

Newman, N., Fletcher, R., Levy, D. A. \& Nielsen, R. K. (2016). Reuters Institute Digital News report 2016. Retrieved from http://www.digitalnewsreport.org/.

Pew Research Center (n.d.). Three Technology Revolutions. Retrieved from http:/www.pewinternet.org/three-technology-revolutions/.

Rosen, J. (2006). The People Formerly Known as the Audience. Retrieved from http://archive.pressthink.org/2006/06/27/ppl_frmr.html.

Sayre, B., Bode, L., Shah, D., Wilcox, D. \& Shah, C. (2010). Agenda Setting in a Digital Age: Tracking Attention to California Proposition 8 in Social Media, Online News, and Conventional News. Policy \& Internet, 2(2): 7-32. 
Shaw, D., McCombs, M., Weaver, D. H. \& Hamm, B. J. (1999). Individuals, Groups and Agenda Melding: A Theory of Social Dissonance. International Journal of Public Opinion Research, 11(1): 2-24.

Shaw, D. \& McCombs, M. (2008). Agenda Setting in the New Media Landscape: Two Perspectives and Approaches to Research, Presentation at Colloquium for Philip Meyer School of Journalism and Mass Communication University of North Carolina at Chapel Hill March 27-28, 2008.

Skogerbø, E. et. al., (2016). Agenda-setting revisited: Social media and sourcing in mainstream journalism. In Bruns, A., Quodling, A. \& Ingebretsen, T. (eds.), The Routledge Companion to Social Media and Politics (pp. 104-120). New York: Routledge.

Smith, M. A., Rainie, L., Shneidermann, B. \& Himelboim, I. (2014). Mapping Twitter Topic Networks: From Polarized Crowds to Community Clusters. Retrieved from http://www.pewinternet.org/2014/02/20/mapping-twittertopic-networks-from-polarized-crowds-to-community-clusters/.

Vargo, C. J., Guo, L., McCombs, M. \& Shaw, D. (2014). Network Issue Agendas on Twitter During the 2012 U.S. Presidential Election. Journal of Communication, 64(2): 296-316.

Weaver, D., McCombs, M. \& Shaw, D. (2004). Agenda-Setting Research: Issues, Attributes and Influences. In Kaid, L. L. (ed.), Handbook of Political Communication Research (pp. 257-282). Mahwah, New Jersey, London: Lawrence Erlbaum Associates, Inc.

Weaver, D. (2007). Thoughts on Agenda Setting, Framing and Priming. Journal of Communication, 57 (1): 142-147.

Weaver, D., Wojdynski, B. W., Mckeever, R. \& Shaw, D. (2010). Vertical and or Versus? Horizontal Communities: Need for Orientation, Media Use and Agenda Melding. Paper presented at the WAPOR (World Association for Public Opinion Research) Annual Conference, Chicago, Illinois, May 1113, 2010. Retrieved from www.academia.edu.

Wohn, D. Y. \& Bowe, B. J. (2016). Micro Agenda Setters: The Effect of Social Media on Young Adults' exposure to and Attitude Toward News. Social Media + Society, 2(1): 1-12. 
Agenda setting in the world of online news:

New questions for new environment 